\title{
A RESPONSE TO WALTER GLANNON
}

\section{JOHN HARRIS}

Walter Glannon has written a stimulating and engaging paper on a subject of increasing importance. The nub of the argument is that an extension of our biological lives would not entail a corresponding extension of our psychological lives and could, beyond a certain point, result in the loss of personal identity. Glannon produces some philosophical and some scientific arguments in support of this claim and concludes that longer life spans would be undesirable.

In responding I should declare two sorts of interests. The first is that I have written about immortality myself, and the second is that like Jonathan Glover I would (as of now) be quite happy to sample a few million years and see how it goes. ${ }^{1}$

\section{QUO VADIS?}

It is unclear where Glannon wants to go, or what he thinks follows from the fact (if it is one) that longer life spans are undesirable. Is it for example that people should not be permitted life extending treatments, or rather that if they are permitted people would be foolish to avail themselves of such opportunities? In the end, and with considerable ambiguity, Glannon concludes that dramatically increased longevity is 'unpalatable' and his arguments 'tell compellingly against genetically manipulating' the human organism to increase life expectancy. If this claim is to be sustained, much more powerful reasons as to why longer life spans would be undesirable than are advanced in the paper need to be produced. Glannon, for example, advances vague claims about the undesirable effects of increasing population. It is not clear that increased longevity for individuals would increase

${ }^{1}$ J. Glover. 1977. Causing Death and Saving Lives. Harmondsworth. Penguin: 57. See also my book, 1988. Clones, genes and Immortality. Oxford. Oxford University Press; and my Intimations of Immortality essay in Science 2000; 288 : 59. 
population size. However, we know about the undesirability of increasing population already and not only have few countries taken very drastic steps to reduce birth rates but also people have seemed resistant to the idea of moderating their desires for children, certainly in the developing world. It is one thing to think something such as having large families undesirable, in the abstract, and quite another to think that this affords a decisive reason for anyone in particular to have a small family when they know how little this will affect the total picture. It is moreover quite another thing to think that legitimate measures could be taken to curtail individual procreative liberty.

\section{WHERE IS THE SPIRIT OF EMPIRICAL ENQUIRY?}

Secondly, some scientific evidence in relation to human memory is advanced which leads to the speculation that the human brain might not be able to cope with memories over the long term. This is an interesting piece of speculation, and it may or may not prove to be the case that the human brain is unable to adapt to assimilate memories over the long term. I would have thought the respectable scientific response to this would be not to insist that producing immortals is undesirable and therefore should not be done, but to say 'this is an interesting hypothesis, let's produce some immortals, see how their brains react and test the hypothesis'. After all, no harm would thereby be done. Either we would produce immortals who had the considerable advantage of very long life, or Glannon is right and no one would exist to be harmed. This is because the successive selves that would exist would have normal life-spans and so no one would suffer whatever harm it is that is predicated upon unacceptably long life or immortality.

The nub of Glannon's argument, however, turns on very detailed arguments about personal identity which make two main claims. Firstly, that a so-called immortal could not retain sufficient psychological continuity to be the same person over an extended life span. This alleged 'fact' leads to the second claim: that this failure in personal identity would undermine the powerful prudential or self-interested motivation for longer lives. Both of these claims seem to be suspect and it is far from clear that even if the first is true the second follows.

\section{THE ARGUMENT FROM SUCCESSIVE SELVES}

The first claim about psychological discontinuity leading to successive selves has much philosophical 'respectability' but has 
never been overwhelmingly convincing. The main support for it in the present paper comes in the form of suggestions that without continuity of memory, continuity of personality and hence personal identity fails. This is not fully convincing. Suppose I have no memories earlier than age ten, does it follow that my physical body is ten years older than me? Secondly, even if the scientific claims about the impossibility of the brain integrating memory and the need to suppress trivial memories is plausible, it doesn't follow that the long lived individual could not supplement physiological memory with supplementary data of many sorts which would provide the appropriate backup. Video histories, photos, records of various kinds could remind even Methuselah of his earlier life even when physiological memory fails, and other Methuselahs could reminisce with him and fill in enough of the gaps. When I look at a photograph of myself aged three playing with a long forgotten toy, I smile both in recognition of myself, aged three, and begin to remember that favourite toy. Of course I don't know whether or not my memory is partly determined by the photograph - but still I remember it! ${ }^{2}$

\section{SUCCESSIVE SELVES AND RATIONAL PRUDENCE}

But finally, the clinching argument seems also to fail. It is unclear why even if Glannon is right about the failure of personal identity over the 800 or 900 years of Methuselah's life, that it follows that prudential or self-interested motivation fails. Suppose 'Methuselah' has three identities, A, B and C and that C can remember nothing of A's life. But suppose the following is also true: A will want to be $\mathrm{B}$ who will remember being $\mathrm{A}$, B will want to become $\mathrm{C}$ who will remember being $\mathrm{B}$ but possibly not remember being $\mathrm{A}$. It is not irrational for $\mathrm{A}$ to want to be $\mathrm{B}$ and not irrational for A to want to be B partly because he or she knows that B will be able to look forward to being C, even though

${ }^{2}$ There is a mass of psychological evidence that our earliest memories are still with us because they have become part of a continuing narrative, constantly re-enforced by stories and other memorabilia. See for example: R.C. Naremore. Making it hang together: Children's use of mental frameworks. Topics in Language Disorders 1997; 18: 16-31; and A. Mccabe, E. Capron and C. Peterson. 1991. The voice of experience: The recall of early childhood and adolescent memories by young adults. Developing narrative structure. McCabe et al. Hillside, N.J. Lawrence Erlbaum Associates: 137-173; E. Reese and N. Brown. Reminiscing and recounting in the preschool years. Applied Cognitive Psychology 2000; 14: 1-17. 
by the time she is $\mathrm{C}$ she won't remember being A. Thus even if personal identity in some strict sense fails over time it is not clear that self interested motivation for physical longevity fails with personal identity. This would remain true however many selves 'Methuselah' turns out to be.

To take a different example: I can have prudential interest in the survival of my children and grandchildren although their identities are different to mine. I know these are successive and different selves but I have an interest in their existence, and in their well being throughout that existence. ${ }^{3}$ No argument Glannon, nor anyone else so far as I am aware, has produced, shows the irrationality of wishing to be Methuselah even if Methuselah is a succession of selves and not a single personal identity. So that when Glannon says that 'there would not be good reasons to care about the future selves' he is surely disingenuous. This is no more true than it is true that I have no good reasons to care about my great-great-grandchildren. It is only irrational (possibly) to think that this will be the self, surviving indefinitely; but it is not irrational to have an interest in creating those successive selves, therefore as an argument for the foolishness of bodily immortality, the argument fails. Many people think that it is rational to discount the far future in favour of the present or near future, even if this were true it would not follow that discounting events in the far future in favour of the near future entailed that the far future counts for nothing. ${ }^{4}$

The argument fails for another related reason. Even if it would be irrational for Glannon's reasons to desire 'immortality' it would not necessarily be undesirable. For even irrational desires or beliefs can merit respect. If this were not so religions could not command rational respect.

So far I have granted that Glannon might be right about both the impossibility of memory permitting a single self to survive over say 800-900 years and that an immortal body would play host to successive mortal souls. I have suggested that even if this were true it would not be irrational to wish to be the first and possibly the second in such a series of selves and to wish the subsequent, successive selves long and happy continuance. ${ }^{5}$ I could take as much if not more pride and interest in my 'line' of

${ }^{3}$ See for example John Rawls' discussion of the Just Savings Principle. 1971.

A Theory of Justice. Cambridge, Mass. Harvard University Press: 284-293.

${ }^{4}$ See for example D. Parfit. 1984. Reasons and Persons. Oxford. Clarendon Press: 158-194.

${ }_{5}$ This is the familiar inconsequential differences paradox. 
genetically identical and bodily (spatio-temporally) continuous selves as many do in their 'line' of descendents.

However, I am far from convinced that I cannot have my cake and eat it, or rather have my descendents and be them too. Glannon's arguments to the contrary seem to me unconvincing. He says: 'There is a limit to the number of projects that can sustain our interest in persisting as persons into the future.... This is due to the limit in our cognitive resources of knowledge and imagination'. As far as imagination goes I am inclined to say 'speak for yourself!' Glannon is clearly nervous about his own confident assertions because he almost immediately retreats to the more doubtful it is doubtful that we could continuously generate a series of projects that could sustain our desire to go on living'. We have moved from certainty to doubt in the space of one sentence. At this point Glannon calls in aid higher authority in the person of Bernard Williams. ${ }^{6} \mathrm{He}$ doesn't cite Williams arguments, but they seem thin and appear more illuminating of the subject of opera than of that of immortality. Williams seems to think that even stuck at an ideal age of say forty-two, one would eventually have done all that forty-two year olds can do and so become terminally bored. But that presupposes that all that fortytwo year olds can do is all that forty-two-year olds could do in 1973. Since the forty-two-year-olds will live forever they will be forever able to increase the ambit of even forty-two-year-old imagination. One might adapt the, probably apocryphal story about Jane Fonda. When someone flatteringly told her that she didn't look 'forty' she allegedly responded 'come on now, this is the 70's - this is what forty looks like now'. We might say 'come on Bernard, this is immortality, this is what forty year old immortals can find to do!'

Glannon soon becomes even more doubtful, suggesting that 'too much memory might compromise our ability to undertake new projects' and hence that even if we could improve memory to maintain continuity of self this might be self-defeating. Again one is tempted to say that it might and then again it might not. Let's try it and see. One, perhaps curious, feature of Glannon's arguments is that when things are uncertain or doubtful he assumes not only that they cannot be done but also that they shouldn't be done. He moves constantly from doubtful possibilities to the conclusion that what may be doubtful will

${ }^{6}$ B. Williams. 1973. The Makropoulos Case: Reflections on the Tedium of Immortality. In Problems of the Self. Cambridge. Cambridge University Press: 82100.

(C) Blackwell Publishers Ltd. 2002 
also be undesirable. I repeat the suggestion that surely the scientifically (and for that matter philosophically) respectable conclusion is to say: 'Let's test this empirically, create immortal bodies and see if they turn out to be immortal selves a well'. And it may all turn out to be very jolly ${ }^{7}$; particularly if the immortals are not suffering from terminal failure of the imagination like Williams and Glannon.

\section{PRACTICAL CONSEQUENCES}

Glannon believes that 'an extended life would appear to be beneficial to each person, but the collective effects of many people having extended lives would mean the lowering of the quality of life for all.... Such a scenario would be especially bad for the young. They would be unfairly burdened by having to pay a disproportionate amount of their income in the form of high taxes to support a large elderly population that would not have worked for many years'. These are very complex matters. A first thing to say is that Glannon seems to have forgotten that these geriatrics may be frozen at 'forty-two' or 'twenty' and therefore may continue to be productive and pay for themselves and for their youthful fellow citizens. ${ }^{8}$ Moreover, since the technology that will create immortals will be expensive and complex, it will for millennia probably be available to a relatively small proportion of the world's population. This creates acute problems of global justice, but indefinitely postpones problems of choice about reproductive policies and population strategies. It may be that we will, in the far distant future, have to face the question of whether or not it is morally preferable to contemplate $\mathrm{x}$ billion people living forever, or $\mathrm{x}$ billion people constantly replacing themselves generation by generation. It may also be, as Glannon rightly notes, that we will have to implement population policies which may include denying the immortals (or some other groups) the right to reproduce. It may be that they will find this a price worth paying - if so Glannon's problems (though not mine) are solved. Glannon contents himself with noting that for 'most people this would be an unpleasant choice'.

\footnotetext{
7 At least on an individual basis. The global issues we will come to in a moment.

${ }^{8}$ Not literally 'frozen' or arrested at a certain age of course but it may be possible to trigger constant regeneration of cells and tissue which would have effects that we might well think of as freezing at a certain age or developmental stage.
} 
But Glannon's implication seems to be that people should be protected from such choices rather than allowed to make them.

\section{GLOBAL JUSTICE}

The justice considerations of creating mortals and immortals who will have to live alongside one another are I believe the only ethical considerations that are distinctly related to the possibility of creating immortals rather than dimensions of other familiar problems like overpopulation. While such 'parallel populations' of mortals and immortals will raise justice issues for any society, since it will be the high income countries that generate the expensive technology required, this will also raise acute global justice issues. However, as I have suggested elsewhere ${ }^{9}$ these problems, while real, may not be easily resolvable. Grant that longevity and even immortality might be a powerful good for individuals and the problem is with us. For we do not normally think it an ethical requirement to prevent good being done to some unless and until it can be done to all. We do not refuse kidney transplants to some, unless and until such life extending treatment can be granted to all, and we do not refuse transplants to the populations of high income countries pending our ability to extend the treatments globally.

\section{GENE STRUCTURES AND MEMORY}

Glannon offers some fascinating speculation about the function of memory in evolutionary biology and how 'certain genes and structures of the brain control memory.' He believes that these speculations support his speculations about how far individuality depends upon assumptions about temporal limitations on continuity of memory. But these are all just that - speculations. He may be right and he may not. Only empirical experiments will decide the issue, experiments of the sort that Glannon seems to rule out.

\section{CONCLUSION}

It remains unclear to me why Glannon thinks that doubts about the possibility of some things make them undesirable. He himself concludes 'my main concern has been with the effects of a longer life on the identity of individual persons and their prudential

${ }^{9}$ See Intimations of Immortality, op. cit. note 1. 
concern about the future. While a life span of 200 years or so might not be as undesirable as genuine immortality, it would be undesirable nonetheless because this period of time would be enough to severely weaken the psychological connections necessary for identity and what matters to us in the future. This unpalatable consequence alone tells compellingly against ... (engineering immortality into humans)'. I may have missed something but I fail to detect any arguments as to why all this would be undesirable and unpalatable (except in individual and global justice terms which are not really an issue for Glannon). Certainly if Glannon's arguments are right it might be foolish and self-defeating to create immortals, but I really can't see where the 'unpalatable' (with its moral overtones) has come from unless Glannon is such a stern rationalist, that rationality and morality are the same thing.

As I hope will be clear from the argument of this response I doubt the arguments from rationality and personal identity that Glannon has produced can be sustained against considerably extending life span. If this is right, the task will be to learn to live creatively with such immortals as are eventually produced, until we have time to see whether experience rather than argument proves Glannon right.

John Harris

The Institute of Medicine, Law $\mathcal{E}$ Bioethics

University of Manchester

Oxford Rd

Manchester M13 9PL

United Kingdom

John.M.Harris@man.ac.uk 